\title{
Growth rate and basal area response curves of four Eucalyptus species on Mt. Wellington, Tasmania
}

\author{
Pyrke, A. F. \& Kirkpatrick, J. B. \\ Department of Geography \& Environmental Studies, University of Tasmania, PO Box 252C, Hoban, Tasmania \\ 7001, Australia; Tel. +612 202834; Fax+612 202928; E-mail A.PYRKE@GEOG.UTAS.EDU.AU
}

\begin{abstract}
The heights, diameters and regrowth basal areas of 22-yr old fire-initiated regeneration of Eucalyptus delegatensis ssp. tasmaniensis, E. unigera, E. coccifera and E. johmstonii were measured over altitudinal, solar radiation and drainage gradients on Mt. Wellington, Tasmania. The growth rate responses to the aftitude gradient-complex vary from linear to curved depending on the performance measure, the species and the gradient. Much of the variation in growtl rate appears to be a direct response to the physical enviromment. However, disparities between trends in growth rate and trends in regrowth basal area are consistent with the hypothesis that competition (sensu Grime 1979) is more important in productive environments and less important in stressful environments. A glasshouse trial with Eucalyptus secdlings indicated that potential growth rates decline with increasing altitude of seed source.
\end{abstract}

Keywords: Competition; Direct gradient analysis; Environmental gradient; Glasshouse experiment; Height growth rate; Seedling.

Nomenclature: Curtis \& Mortis (1975).

\section{Introduction}

The idea that the performance of plant species along environmental gradients can be represented by symmetric, bell-shaped curves has been recognised in recent years to be a somewhat idealized perception of the real world. While the response curves of some species to environmental gradients do appear to be symmetric and unimodal, a variety of responses have recently been found (c.g. Werger et al. 1983; Minchin 1989).

The variety in response curves is not surprising given the marked differences in selection of performance and envirommental measures between authors (Mueller-Dombois \& Ellenberg 1974; Austin \& Austin 1980; Austin et al. 1985; Whittaker 1956; Waring \& Major 1964; Ogden \& Powell 1979; Villagrán et al. 1981; Werger et al. 1983; Robertson et al. 1984; Minchin 1989). Different kinds of performance measures may produce different response curve shapes (Austin \& Smith
1989), and the ecologically relevant metric of an environmental gradient is not usually readily apparent. For example, basal area may give a curved response in a situation where stem diameter gives a linear response, and the treatment of precipitation as Euclidean will give a different form of response than a moisture availability index that includes an evaporation component.

The shape of a response curve of a species grown in monoculture can be modified when it is grown in the presence of other species (Ellenberg in Mueller-Dombois \& Ellenberg 1974; Austin \& Austin 1980; Austin et al. 1985). The fundamental niche of a plant species is the environmental hypervolume it might occupy in the absence of interference from other species. This 'physiological response' is very different from the 'ecological response' (sensu Mueller-Dombois \& Ellenberg 1974) that manifests itself in the realized niche. Fresco (1982) found that, in extreme environments, the 'physiological' and 'ecological' response curves of a species tend to be quite similar in shape, suggesting that competition may not be important in stressful environments, a conclusion consistent with that of Grime (1979).

Intraspecific genetic variation may be important in explaining the performance of species along environmental gradients. The attenuation of abundance of a species at opposite ends of a gradient may often result from different abiotic or biotic stresses, requiring different genetic responses (see, for example Gilfedder 1988). Intraspecific genetic variation in growth-rate potential has been well documented for Eucalyptus species in Australia (e.g. Barber \& Jackson 1957; Ashton 1958; Parsons 1968; Ladiges 1974). Genotypes from wetter/ warmer environments are usually faster growing than those from drier/cooler environments.

Austin (1985) stressed that direct gradient analysis should be based on the most ecologically relevant variables that can be measured. Altitude is a gradient complex involving a number of environmental variables which may be correlated to a greater or lesser extent (Whittaker 1978; Kessel 1979; Austin 1980). The duration of temperatures suitable for photosynthetic activity usually declines with altitude, while precipitation, duration of snow cover, wind speed, frost incidence and 
cloud cover usually increase with altitude. While temperature usually has a roughly linear relationship with altitude, other variables can have more complicated relationships (Lee 1978).

In this paper, we determine the basal area and growth rate responses of four major canopy species of the genus Eucalyptus to altitudinal, solar radiation and soil moisture gradients on Mt. Wellington, Tasmania. We assess the utility of these data in addressing the hypothesis that competition is less severe in physiologically stressful environments, and in developing hypotheses on the causes of altitudinal zonation. We believe this study to be the first recording the natural differential growth of species within the same synusia over major environmental gradients in the field. It was made possible by a fire that burnt the whole mountain in 1967, causing even-aged regeneration. A glasshouse provenance trial on seedlings of three canopy species assesses the degree to which genecological variation in seedling growth rates and shoot/root ratios of the three major tree species in the study area reflect theoretical expectations and the pattern of growth of trees.

\section{Material and Methods}

\section{The study area}

Mt. Wellington rises $1270 \mathrm{~m}$ above the Derwent River and the city of Hobart in southeastern Tasmania $\left(42^{\circ} 54^{\prime} \mathrm{S}, 147^{\circ} 14^{\prime} \mathrm{E}\right)$. The vegetation is largely composed of native species on undisturbed substrates, at least down to $500 \mathrm{~m}$ altitude. The study area in this paper encompasses the eastern side of Mt. Wellington, including north through to south slopes, between $400 \mathrm{~m}$ and the treeline $(1240 \mathrm{~m})$.

The surface geology of the study area is predominantly Jurassic dolerite. Although minor outcrops of sedimentary rocks do occur, these were not sampled. Talus slopes cover a considerable proportion of the study area. The soils have formed mainly on rocky mantles of Pleistocene solifluction deposits. These yellow-brown soils are not differentiated into horizons on well drained sites, but a distinct peat horizon develops on poorly-drained areas (Loveday 1955; Nicolls 1961; Caine 1983).

At $720 \mathrm{~m}$ altitude, the mean daily maximum temperatures are $16^{\circ} \mathrm{C}$ in January and $6.6^{\circ} \mathrm{C}$ in July, while the mean daily minima are $6.7^{\circ} \mathrm{C}$ and $1.5^{\circ} \mathrm{C}$ respectively. At $1250 \mathrm{~m}$ the mean daily maxima are $12.8^{\circ} \mathrm{C}$ in January and $1.9^{\circ} \mathrm{C}$ in July, with mean daily minima of $4.4^{\circ} \mathrm{C}$ and $-2^{\circ} \mathrm{C}$ for the same months. Nune \& Colhoun (1986) recorded a lapse rate in maximum temperature on Mt. Wellington of $0.75^{\circ} \mathrm{C}$ per $100 \mathrm{~m}$ of altitude, from six stations over 12 months. Frost and snow are rare or absent during the summer months at lower altitudes. However, frost and snow may occur at the summit in summer, although less frequently than in winter. At $720 \mathrm{~m}$ altitude, the mean annual rainfall is $1367 \mathrm{~mm}$ with relatively little monthly variation (mean $113.9 \mathrm{~mm}$ per month, $\mathrm{SD}=12.7 \mathrm{~mm}$ ).

The burning of Mt. Wellington by indigenous Tasmanians was documented by early European explorers, but the pre-European fire regime of Mt. Wellington is not known. Europeans have inhabited the surrounding lowlands for nearly $200 \mathrm{yr}$, during which time Mt. Wellington has been burnt frequently, often by intense and widespread fires. The last fire to burn in the study area was in 1967. It burnt virtually the entire Mt. Wellington massif. There have been no fires in the study areal since this date.

\section{Rainfall and cloud base levels}

Four rain-gauges were positioned at altitudes of 830 , 1030,1100 and $1180 \mathrm{~m}$ on Mt. Wellington during March and April 1989. The cloud base level on Mt. Wellington was estimated visually from Hobart from March until September 1989 , at 9.00 and either 15.00 or 17.00 . Data on the summer cloud base were obtained from the Bureau of Meteorology, Hobart.

\section{Vegetation and tree sampling}

The study area encompasses the complete altitude range of the four dominant tree species that are the subject of this study: Eucalyprus delegatensis ssp. tasmaniensis, E. umigera, E. johnstonii and E. coccifera. $10 \mathrm{~m} \times 10 \mathrm{~m}$ quadrats were distributed over the range of altitudes and aspects within the study area (Fig. 1). The sampling strategy targeted a particular altitude and aspect. The tallest basal coppice or seedling regrowth of 1967 age was then selected excluding regrowth under the vertical projection of the canopy of the larger trunk resprout trees, which are known to suppress growth (Bowman \& Kirkpatrick 1986). A total of 66 quadrats were recorded in this manner while a further eight quadrats of the same size were placed along a transect across a waterlogged area. The distance between these quadrats was stepped out to 25 pace intervals following the 860 metre contour.

Within each quadrat, all the vascular plant species were recorded. For each species, the cover/abundance was estimated as follows: $+=$ few individuals, cover $<$ $5 \% ; 1=$ many individuals, cover $<5 \% ; 2=\operatorname{cover} 5-$ $25 \% ; 3=$ cover $25-50 \% ; 4=$ cover $50-75 \% ; 5=$ cover $75-100 \%$. The altitude, aspect, slope and rock cover were also recorded. Altitude was estimated from a 


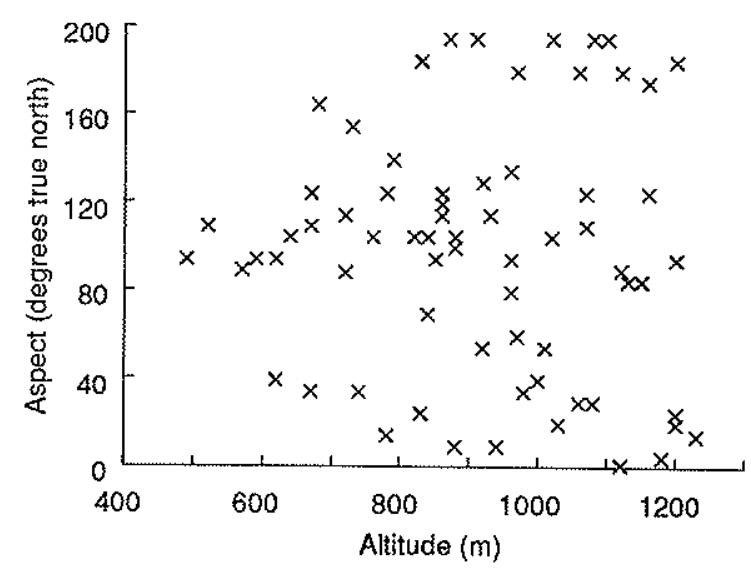

Fig. 1. The distribution of the 74 quadrats in terms of altitude and aspect.

topographic map to within $20 \mathrm{~m}$. Aspect and slope was measured with a compass and clinometer respectively. Rock cover was estimated visually on a five-class scale, using the five numeric intervals described above for species cover. An index of the yearly total solar radiation potentially received by a site was calculated from aspect and slope (Nunez 1983).

The following parameters were also measured in the quadrats:

1. The height of the tallest stem and the diameter over bark of the stem with the largest girth for each Eucalyptus species - for multi-stemmed plants, the height and diameter of the largest stems were measured even if they were outside the quadrat, as long as at least one stem was rooted within the quadrat. Heights were measured either with measuring poles or by trigonometry with a clinometer and tape measure. Diameters were measured with a tree diameter tape, $1.3 \mathrm{~m}$ above ground level. All branches of branching stems were measured, when the branching occurred between ground level and $1.3 \mathrm{~m}$.

2. The number of individual plants greater than $1.3 \mathrm{~m}$ tall of each Eucalyptus species was counted. Multistemmed individuals were included in the tally provided that at least one of the stems was rooted within the quadrat.

3. In a subset of quadrats which included the transect sites, a total stem count was made for each species.

4. The basal area at $1.3 \mathrm{~m}$ above-ground was estimated for each Eucalyptus species by the Bitterlich variable radius method (Mueller-Dombois \& Ellenberg 1974), sighting from the centre of the quadrat. Coppice regrowth and trunk-resprouted trees were measured separately. The mean stem diameter was derived from basal area and stem density in the quadrats in which the stem density count was recorded by species.

The 1967 age class of basal coppice and seedlings was readily identifiable in the field. Older trees nearly always had some fire scarring that identified them as older than $22 \mathrm{yr}$. This assumption was confirmed by increment coring one large tree that was assumed to be $22 \mathrm{yr}$ old, for each of E. coccifera, E. umigera and $E$. delegatensis.

\section{Seedling provenance trials}

Seed was collected from Mt. Wellington in March 1989 from three species and three altitudes (m) per species as follows: E. delegatensis 640,750, 900; E. umigera $750,900,1050 ;$ E coccifera $900,1050,1200$. There were six separate collection sites. At $900 \mathrm{~m}, E$. coccifera and $E$. urnigera were collected from one site while E. delegatensis was collected from another. The collection sites were on northern and eastern aspects. Seed was collected from five subjectively selected parent trees per species at each site.

The 45 seed lots (i.e. 3 species $\times 3$ sites $\times 5$ parents) were kept separate throughout the experiment. The seed was placed on moist filter paper in petri dishes, stratified for 40 days at $3{ }^{\circ} \mathrm{C}$ and germinated in a dark incubator at $20^{\circ} \mathrm{C}$ with periodic exposure to light. The seedlings were placed in cylindrical plastic pots using a potting mix composed of sandy loam, sand, peatmoss, powdered dolomite and fertilizer. There were up to 15 pots per provenance, with three replicates per parent if sufficient germinants were available. Initially, there were up to three seedlings per pot but these were thinned out to leave the biggest and healthiest seedling in each pot.

The seedlings were randomly arranged in a glasshouse for 12 weeks from July until September 1989 and were watered daily. The glasshouse was heated and the photoperiod was maintained at 16 hours per day with artificial light supplementing natural light. The daily maximum temperature in the glasshouse was approximately $17^{\circ} \mathrm{C}$ at the start of the trial, but this temperature had increased to $28^{\circ} \mathrm{C}$ by the end of the trial, with brief peaks of $38^{\circ} \mathrm{C}$ in the final two weeks. The average daily minimum temperature was a fairly constant $10^{\circ} \mathrm{C}$.

The heights of the shoots and oven-dried weights $\left(85^{\circ} \mathrm{C}\right)$ of the separated shoots and roots were measured at the end of the trial period.

\section{Data analysis}

Response curves are presented for altitude, solar radiation and an indirect ordination score that was closely related to variability in surface rockiness and soil drainage. The eucalypts were excluded from the ordination analysis on vascular plants to help avoid circularity (Austin 1972, 1980). An insufficient range of values of rock cover were recorded to present response curves for 


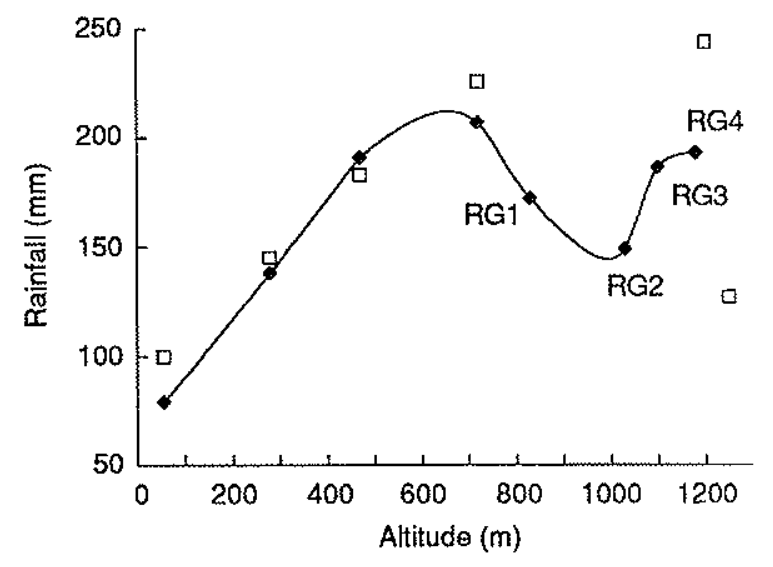

Fig. 2. Total rainfall from Hobart to the Mt. Wellington summit in the months of March and April. $\square=$ long-term average; -1989 .

this variable directly.

The floristic data were analysed using global nonmetric multidimensional scaling (GNMDS) in the programme MDS (Minchin 1990). The Bray-Curtis coefficient (Bray \& Curtis 1957) was used on transformed cover values which were standardized to species maxima. The transformation used the midpoints of the cover classes with the exception of the + class $(t=0.5)$. The GNMDS was performed in 1 to 5 dimensions, using 40 random starting configurations. The appropriate number of dimensions was considered to be where the addition of one more dimension gave only a small reduction in stress, compared to the previous increase in dimensionality.

A vector fitting algorithm in DECODA (Minchin 1990) was used to find the maximum correlation between environmental variables and the GNMDS solution and to apply a Monte Carlo significance test based

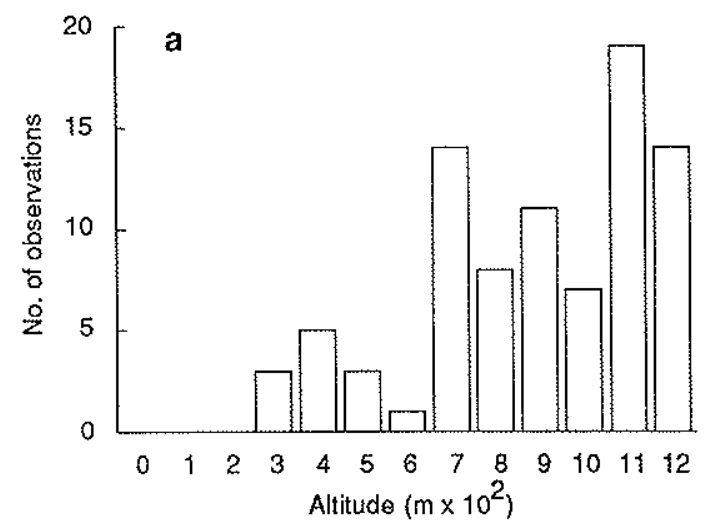

on 999 permutations. The variables fitted were altitude, aspect, slope, solar radiation index and rock cover.

The data were stratified by altitude, solar radiation and rock cover for presentation of response curves. The ranges of the values for the constant variables were chosen to maximise the number of samples. There was an element of subjectivity involved in choosing the ranges of values, which are presented to indicate the degree of stratification.

The response curves are either simple linear or quadratic regressions, presented with the original data points from individual quadrats. A quadratic rather than a simple linear regression was used when it provided a considerable increase in the $R^{2}$ statistic for non-significant regressions; or for significant regressions, if the $x^{2}$ term was significant at the $p=0.05$ level. Response curves are presented for growth rate, as measured by either maximum tree height or maximum stem diameter after $22 \mathrm{yr}$, and basal area.

Multiple linear regressions were performed on the maximum height values in quadrats, for $E$. delegatensis, $E$. urnigera and $E$. coccifera. The predictor variables were altitude, solar radiation and rock cover. The ten quadrats from waterlogged sites were excluded from this analysis.

Seedling height data were analysed by linear regression and a $t$-test, while analysis of variance was used for the ratios of seedling shoot/root dry weights.

\section{Results}

The data collected in March and April 1989 suggest that the rainfall gradient between $700 \mathrm{~m}$ and the summit of Mt. Wellington is not linear (Fig. 2). The cloud base record is incomplete for the period covered, but a total of

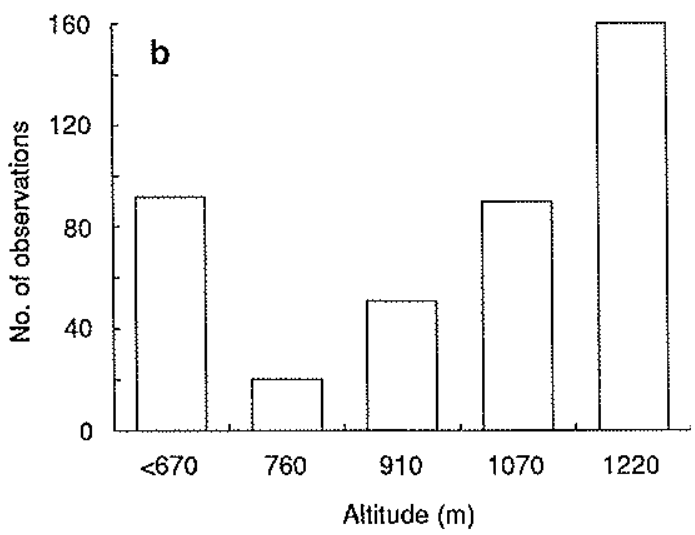

Fig. 3. (a) Frequency of cloud base levels observed on ME. Wellington, recorded (wice daily from March to September 1989, (b) Cloud base observations at 15.00 from the Bureau of Meteorology for December, January and February (December 1979 - February 1989). 480 of the 893 observations were higher than the summit of Mt. Wellington. 
243 observations were made. For 158 of these observations the cloud base, if present at all, was higher than the summit of Mt. Wellington. The remaining 85 observations suggest that the cloud base is more persistent above $700 \mathrm{~m}$ than below that altitude, as do the Meteorological Burcau observations from summer (Fig. 3a, b).

The three-dimensional GNMDS solution (stress = 0.145 ) was considered to have the appropriate number of dimensions, after examination of the stress values of ordinations ranging from one to five dimensions. Altitude, solar radiation and rock cover were found to have highly significant correlations with separate trends in the total vascular plant composition (excluding eucalypts) (Table 1).

The height growth rates of $E$. delegatensis and $E$. coccifera decrease with increasing altitude on sites with yearly solar radiation values $<5.0 \mathrm{MJm}^{-2} \times 10^{3}$ ( sheltered southern/eastern aspects), with very little difference between any species at an altitude where more than one species occurs (simple linear regressions; Fig. 4a):

$$
\begin{array}{llll}
\text { E. delegatensis: } & n=7, & R^{2}=0.90, & p<0.002 ; \\
\text { E. coccifera: } & n=15, & R^{2}=0.92, & p<0.0001 ; \\
\text { E. unnigera: } & n=8, & R^{2}=0.47, & p=0.06
\end{array}
$$

On sites with yearly solar radiation values $>5.0 \mathrm{MJm}^{-2}$ $\times 10^{3}$ (exposed northern aspects), the height growth rate response to altitude of $E$. umigera appears to be curved, although the quadratic regression is not significant ( $n=$ $\left.9, R^{2}=0.34, p=0.28\right)$. The responses of $E$. delegatensis and $E$. coccifera are linear $\left(n=5, R^{2}=0.86, p<0.025\right.$ and $n=11, R^{2}=0.70, p<0.002 ;$ Fig. 4b). E. delegatensis grows much faster than $E$. coccifera and $E$. umigera on sites where they co-occur on exposed aspects (Fig. 4b).

Linear trends in growth rates are observed for stem diameters on sheltered aspects for $E$. delegatensis and $E$. coccifera (simple linear regressions; Fig. 4c):
E. delegatensis:
$n=7, \quad R^{2}=0.59$,
E. coccifera:
$n=15, \quad R^{2}=0.84$,
$p<0.05$;
E. umigera:
$n=8, \quad R^{2}=0.41$
$p<0.0001$;
$p=0.09$.

However, stem diameter growth rates are curved for $E$. urnigera and $E$. coccifera on exposed aspects (quadratic regressions), with no trend (simple linear regression) for E. delegatensis (Fig. 4d):

$$
\begin{array}{llll}
\text { E. unigera: } & n=9, & R^{2}=0.65, & p<0.05 \\
\text { E. coccifera: } & n=11, & R^{2}=0.74, & p<0.005 ; \\
\text { E. delegatensis } & n=5, & R^{2}=0.06, & p=0.7 .
\end{array}
$$

No significant regressions could be fitted for basal areas on sheltered aspects (Fig. 4e):
E. delegatensis: quadratic,
E. umigera: simple linear,
$n=9, R^{2}=0.44, \quad p=0.2$
E. coccifera: simple linear,

\begin{tabular}{|c|c|c|c|c|c|}
\hline \multirow[t]{2}{*}{ Environmental variable } & \multirow{2}{*}{\multicolumn{2}{|c|}{$R_{\max }$}} & \multicolumn{3}{|c|}{ Angle to axes } \\
\hline & & & 1 & 2 & 3 \\
\hline Altilude & 0.88 & का: & 34 & 61 & 106 \\
\hline Aspect & 0.54 & 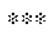 & 79 & 64 & 29 \\
\hline Slope & 0.43 & $\therefore *$ & 158 & 102 & 72 \\
\hline Rock cover & 0.48 & $\% *$ & 100 & 15 & 79 \\
\hline Solar radiation & 0.64 & wos & 93 & 110 & 160 \\
\hline$* * *=p<0.001$ & & & & & \\
\hline
\end{tabular}
$n=8, R^{2}=0.02, \quad p=0.7$;
$n=15, R^{2}=0.19, \quad p=0.1$.

Table 1. Maximum comelations between environmental variables and fitted vectors for the three-dimensional GNMDS configuration, indicating angles for the ordination axes.

On exposed aspects the regressions were (Fig. 41):
E. delegatensis: quadratic,
$n=6, \quad R^{2}=0.91, p<0.05$
E. coccifera: quadratic, $\quad n=11, R^{2}=0.63, p<0.025$; $\left(p=0.06\right.$ for the $x^{2}$ term);
E. urnigera: simple linear, $n=9, R^{2}=0.21, p=0.2$.

The sequence of species replacement is E. delegatensis, E. umigera, E. coccifera with increasing altitude on all aspects (Fig. 4e,f).

The total basal area of all trees, including larger trunk-resprouted trees, declines linearly in response to altitude on sheltered aspects, with a more pronounced response on exposed aspects (linear regressions: sheltered southern and eastern slopes, $n=23, R^{2}=0.47, p<$ 0.001 ; exposed northern slopes, $n=14, R^{2}=0.78, p=$ 0.0001 ; Fig. 5) From $720-850 \mathrm{~m}$, E. delegatensis forms most of the basal area on exposed aspects, while $E$. urnigera dominates on sheltered aspects (Fig. 6a), but height growth rate superiority of $E$. delegatensis over $E$. umigera is only observed on exposed aspects (Fig. 6b). There is no clear trend in the response of $E$. coccifera to the solar radiation gradient at $1100-1200 \mathrm{~m}$ (Fig. 7). E. delegatensis appears to grow faster on exposed aspects compared to sheltered aspects at the higher rather than lower end of its altitude range (Fig. 8).

The response of $E$. unigera to the inferred moisture gradient, represented by ordination scores from the vector fitted for rock cover, are apparently linear for height growth rate (simple linear, $n=18, R^{2}=0.38, p<0.01$; Fig. 9 a), but curved for basal area (quadratic, $n=16, R^{2}=0.40$, $p<0.05$; Fig. 9b). The performance of $E$. coccifera declines with increasing waterlogging for height growth rate (simple linear, $n=11, R^{2}=0.44, p<0.05$; Fig. 9c) and perhaps basal area (simple linear, $n=10, R^{2}=0.27$, $p=0.1$; Fig. 9d). No significant trends are evident for $E$. johnstonii for either height growth rate (simple linear, $n$. $=9, R^{2}=0.27, p=0.2 ; \mathrm{Fig}$. 9e) or basal area (simple linear, $n=10, R^{2}=0.07, p=0.5 ;$ Fig. 9f), although the trends suggest a decline in performance with increased waterlogging. The response of the total basal area of all species 

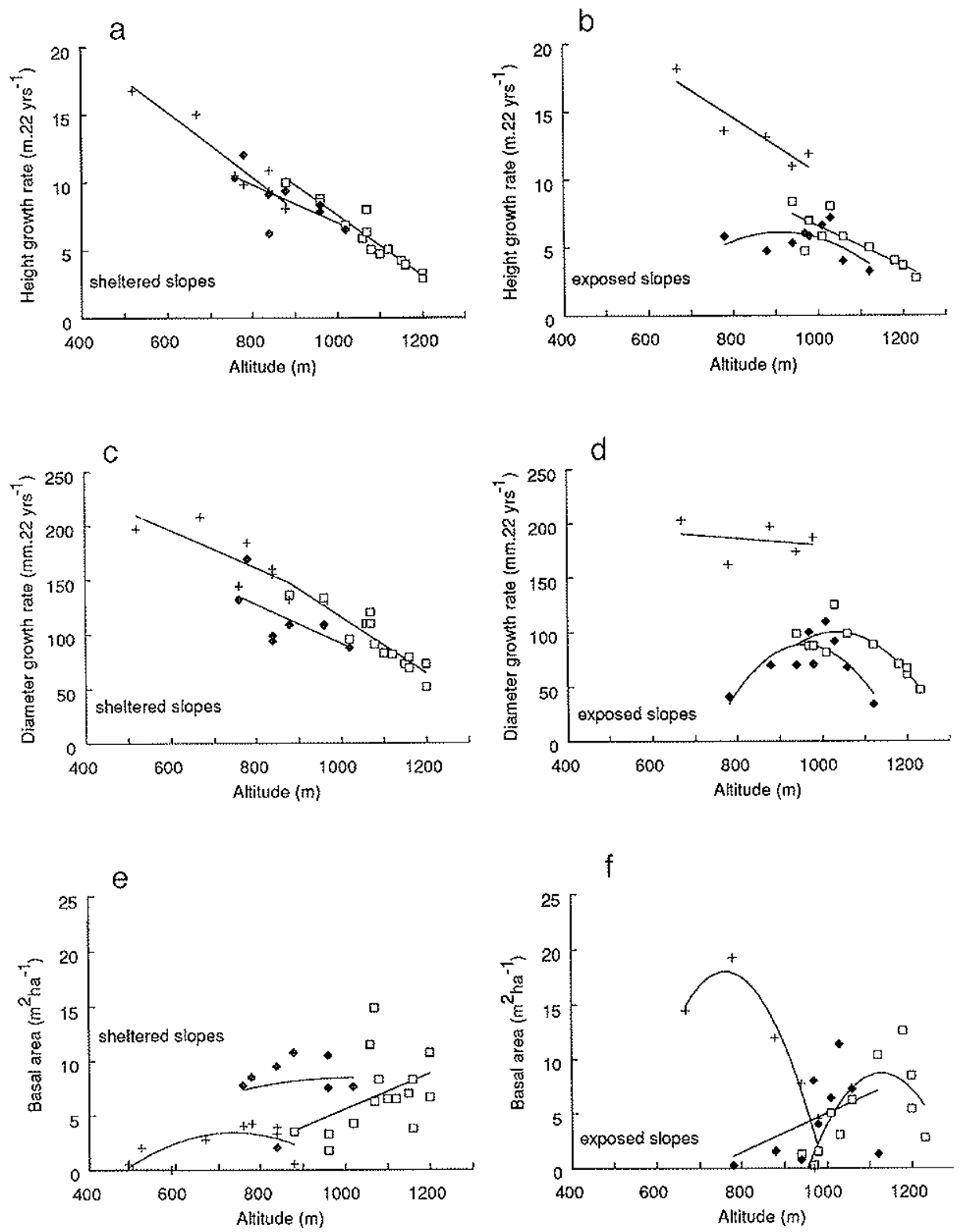

Figs. 4a-f. The response of three Eucalyptus species to altitude in terms of height growth rate, diameter growth rate and basal area. Stratification: rock cover classes $3-4$ for all graphs; solar radiation $<5.0 \mathrm{MJm}^{-2} \times 10^{3}$ ( Fig, $\left.4 \mathrm{a}, \mathrm{c}, \mathrm{e}\right)$; $\geq 5.0 \mathrm{MJn} \mathrm{m}^{-2} \times 10^{3}$ (Fig. $4 \mathrm{~b}, \mathrm{~d}, \mathrm{f}$ ); two additional watelogged quadrats omitted from Fig. $4 a, \mathrm{c}, \mathrm{e} .-\square-$ E. coccifera; $-=$ E. umigera; $\longrightarrow=$ E. delegatensis.

to the inferred moisture gradient is also curved (quadratic, $n=19, R^{2}=0.65, p<0.001$; Fig. 10 ).

The relationship between maximum stem diameter and mean stem diameter per quadrat is linear for both $E$. coccifera $\left(n=22, R^{2}=0.49, p<0.001\right.$, excluding the transect quadrats) and $E$, unigerc $\left(n=17, R^{2}=0.77, p\right.$ $<0.0001)$. The number of stems per plant increases with increasing altilude for both of these species, although E. umigera has more stems per plant than E. coccifera. at any given altitude (Fig. 11). However, on waterlogged sites on the transect at $860 \mathrm{~m}$ altitude, the degree of multi-stemming does not fit this trend for either species (Fig. II). The ratio of maximum stem diameter to mean stem diameter of $E$. coccifera decreases with increasing altitude (without transect quadrats, Spearman rank $R=-0.59, p<0.01)$.

Altitude and rock cover, but not solar radiation, make a significant contribution to the nultiple regression of the height growth rate of E. coccifera $\left(R^{2}=0.79\right.$; $n=35$; attitude, $p<0.0001$; rock cover, $p<0.01$ ); regression equation:

$h=26.254-0.018 a-0.021 r c$. 


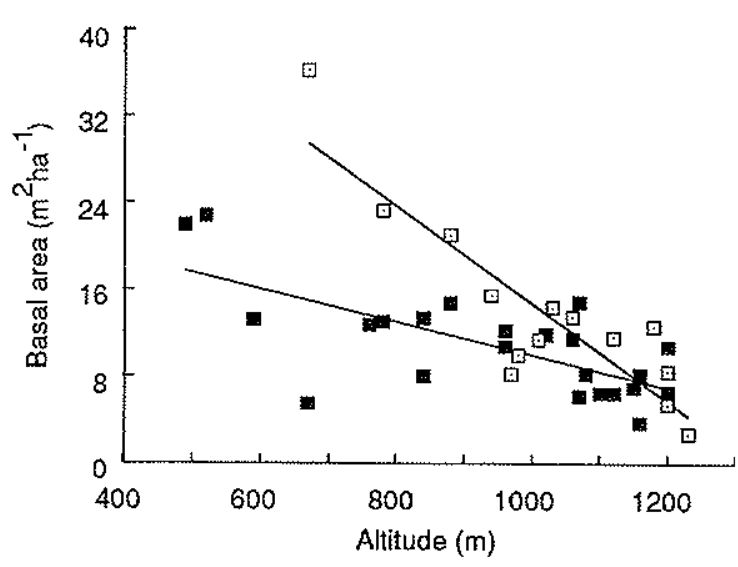

Fig. 5. The response to altitude of the total basal area of all trees, inchuding larger trunk resprout trees. Stratification: rock cover classes $3-4$. $-2-=$ solar radiation $<5.0 \mathrm{MJm}^{-2} \times 10^{3}$; $-\square=$ solar radiation $\geq 5.0 \mathrm{MJm}^{2} \times 10^{3}$.

In the multiple regression of E. delegatensis heights, all three variables are significant $\left(R^{2}=0.70 ; n=22\right.$; altitude, $p<0.001$; solar radiation, $p<0.01$; rock cover, $p<$ $0.025)$; regression equation:

$h=14.519-0.020 a+3.350 s r-0.045 r c$.

In the multiple regression of E. urnigera heights, again all three variables make a significant contribution $\left(R^{2}=\right.$ $0.62 ; n=33$; altitude, $p<0.01$; solar radiation, $p<$ 0.001 ; rock cover, $p<0.05$ ); regression equation:

$h=26.809-0.008 a-2.205 s r-0.024 r c$

Height growth decreases with increasing solar radiation for E. umigera, but increases for E. delegatensis (Fig.

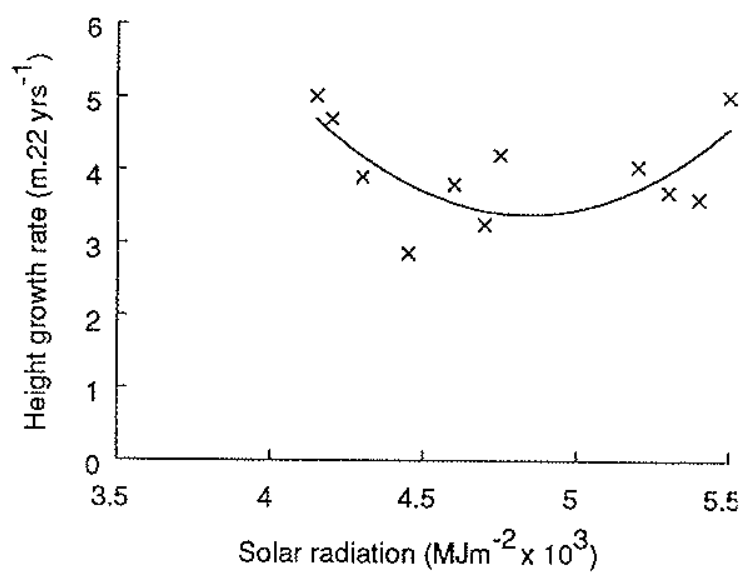

Fig. 7. The response of Eucalyptus coccifera to solar radiation in terms of height growth rate. Stratification: altitude 1100 $1200 \mathrm{~m}$; rock cover classes $3-4$.
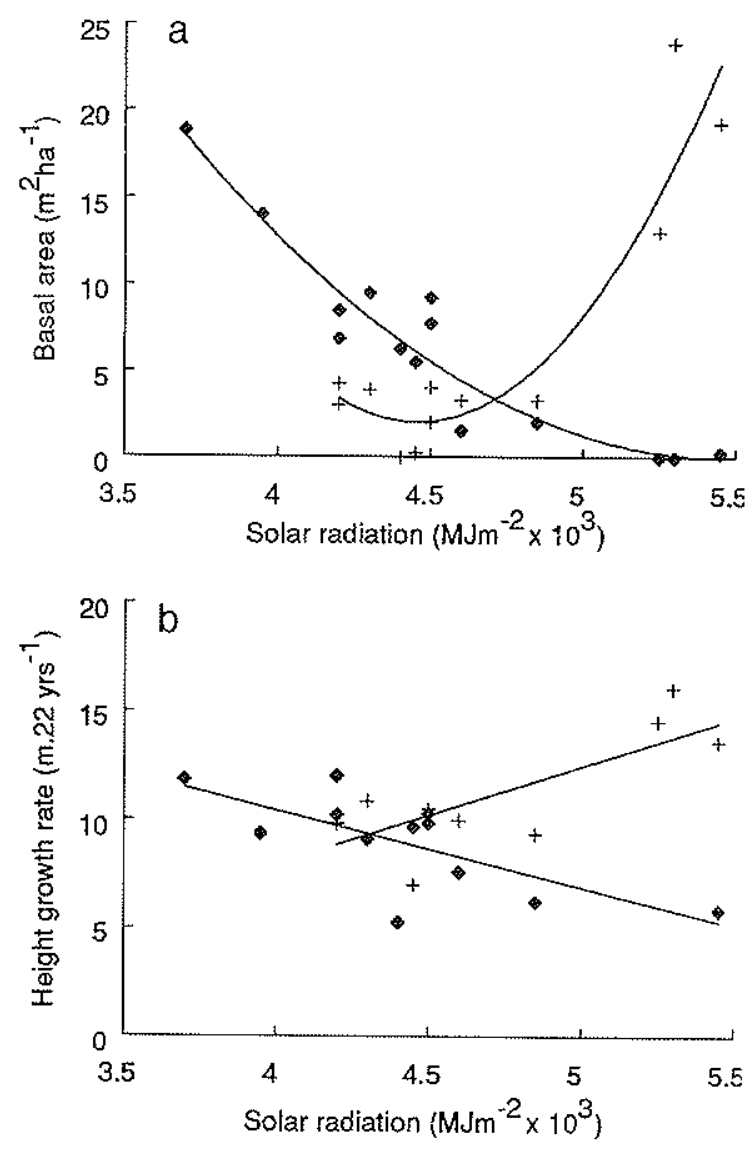

Fig. 6a-b. The response of two Eucalyptus species to solar radiation in terms of basal area and heiglu growth rate. Stratification: altitude $720-850 \mathrm{~m}$ : not stratified for rock cover.

$-1-$ E. unigera; $+-=$ E. delegatensis.

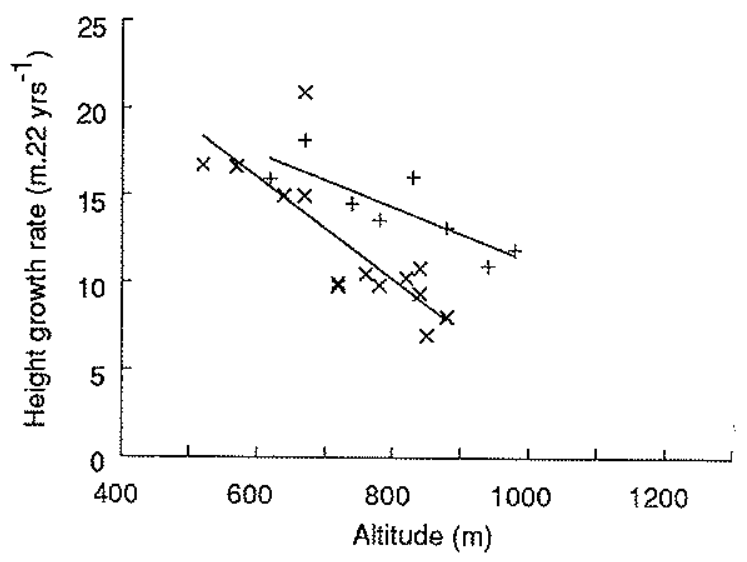

Fig. 8. The response of Eucalyphus delegatensis to altitude in terms of height growth rate, indicaing the effect of solar radiation. Not stratified for rock cover $x=$ solar radiation $<$ $5.0 \mathrm{Mm}^{-2} \times 10^{3} ;+=$ solar radiation $\geq 5.0 \mathrm{MJm}^{-2} \times 10^{3}$. 
a

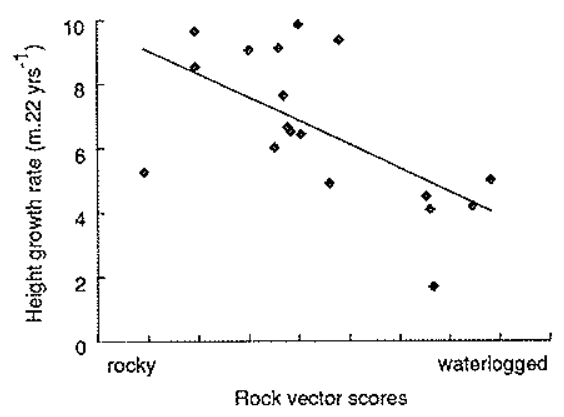

C

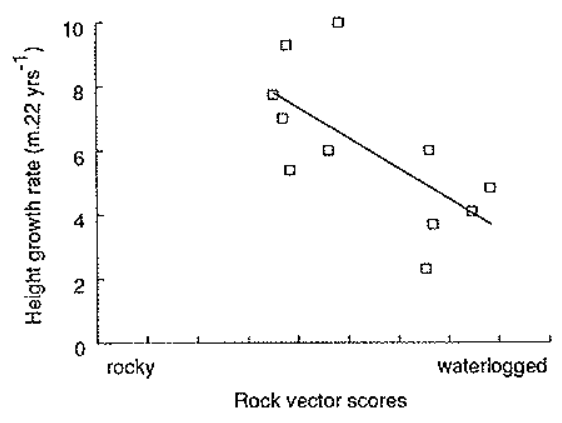

e

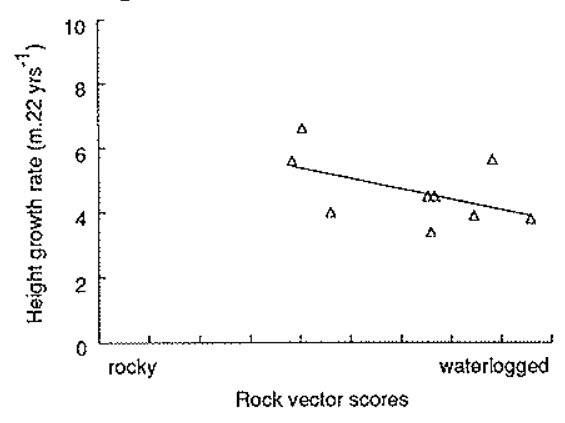

b

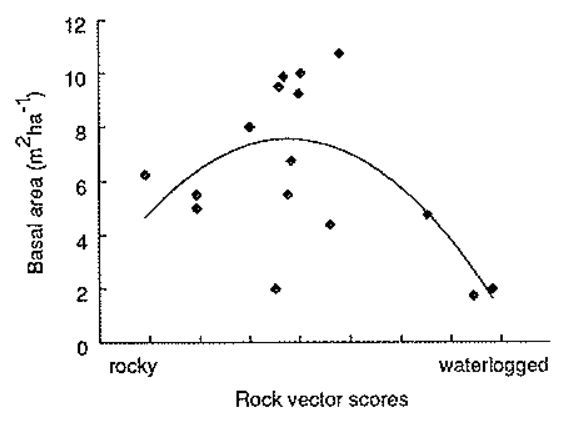

d

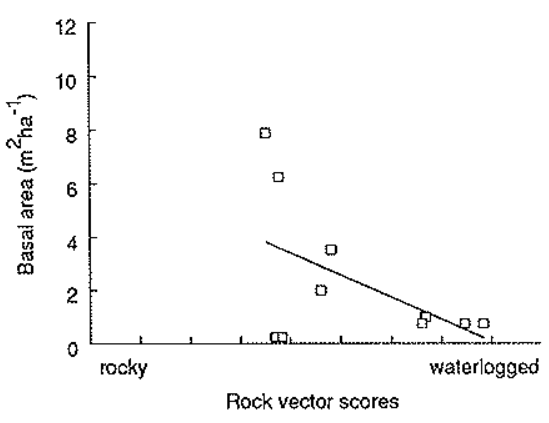

$f$

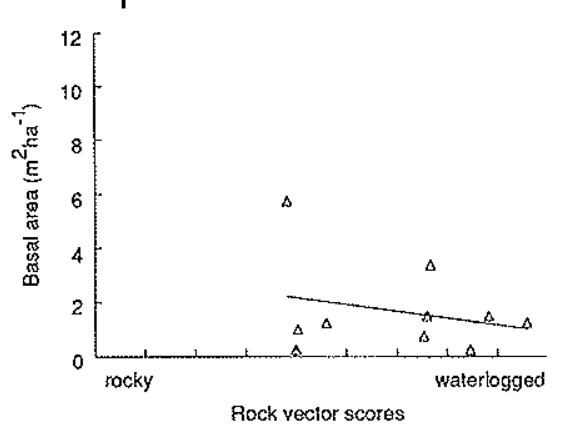

Fig. 9a-f. The response of three Eucalyptus species to an inferred moisture gradient in terms of height growth rate and basal area. The moisture gradient is inferred from ordination scores for a vector fitted to rock cover. Stratification: altitude $820-930 \mathrm{~m}$; solar radiation 4.1 $4.5 \mathrm{MJm}^{-2} \times 10^{3}$.

- E. unigera, $\square=E$. coccifera; $\triangle=$ E. johnstonii. 6b). Height growth decreases with increasing rockiness for all three species.

A linear regression of the seedling height data with all three species pooled together, suggests that growth rate amongst seedlings declines with the altitude of the parents $\left(R^{2}=0.094, p<0.001, n=118\right.$, Fig. 12a), Given this result and the linear trends in the adult growth rates in the field in response to altitude on sheltered aspects (Fig. 4a), a test of a directional hypothesis is warranted. A comparison of the mean seedling heights from the lowest and highest altitude parents, using the total variance from all three populations within a species, and then summed for all three species (summing the differences between means and the pooled variances) (B. Brown pers. comm.), indicates that the higher altitude populations have slower mean height growth rates than the lower altitude populations $\left(t_{109}=2.71, p<0.005\right)$.
Additionally, the probability of all three species having the three sample means in the same rank order, decreasing with increasing altitude of seed source, is 0.0046 (i.e. $1 / 6 \times 1 / 6 \times 1 / 6$, Fig. 12a). The seedlings of E. umigera are significantly taller than those of E. delegatensis when the samples are pooled from 750 and $900 \mathrm{~m}\left(t_{49}=\right.$ $2.05, p<0.05)$.

Analysis of variance performed separately for each species found intraspecific differences in shoot/root ratios between the three altitudinal populations of E. coccifera and E. urnigera (one-way ANOVA on log transformed data: $\mathrm{F}_{2.36}=8.65, p<0.001$; and $\mathrm{F}_{2.39}=$ $5.25, p<0.01$ respectively), but not for $E$. delegatensis $\left(\mathrm{F}_{2.34}=0.84, p>0.4\right)$. In pair-wise intraspecific tests, the $750 \mathrm{~m}$ population of E. umigera is significantly different from the other two populations $(p<0.05)$, although the means suggest that the $900 \mathrm{~m}$ population fits the 


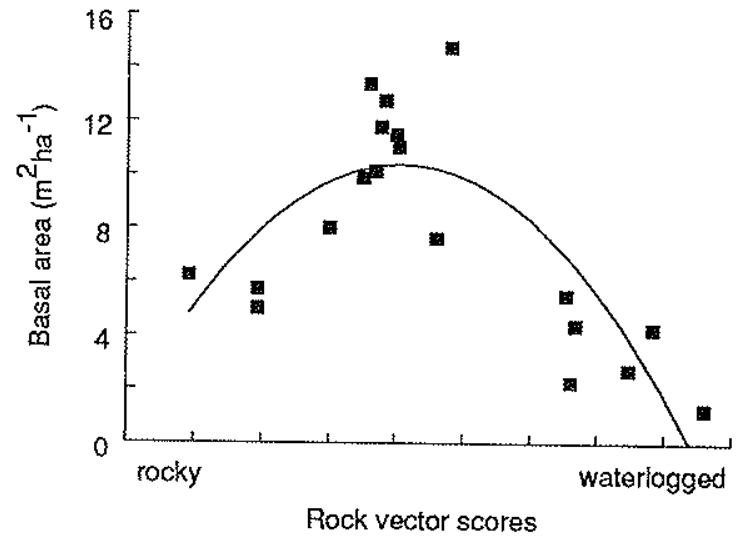

Fig. 10. The total basal area of coppice regrowth in response to an inferred moisture gradicnt derived from ordination scores. Stratification: altitude $820-930 \mathrm{~m}$; solar radiation $4.1-4.5$ M.Im-2 $\times 10^{3}$.

same trend (Fig. 12b). In the pair-wise tests for $E$. coccifera, the $1200 \mathrm{~m}$ population has a significantly larger shoot/root ratio than the other two populations $(p<0.05 ;$ Fig. 12b).

\section{Discussion}

The meaning of the environmental gradients

Our and other data suggest that the relationship between altitude and rainfall between $700 \mathrm{~m}$ and the summit of Mt. Wellington is not linear (Fig. 2), and that there is a relatively sharp break above $700 \mathrm{~m}$ in the duration of mist (Fig. 3a) and snow cover (pers. observ.). The data of Nunez \& Colhoun (1986) indicate that there is a linear relationship between minimum and maximum daily temperatures and altitude. The ecological impor-

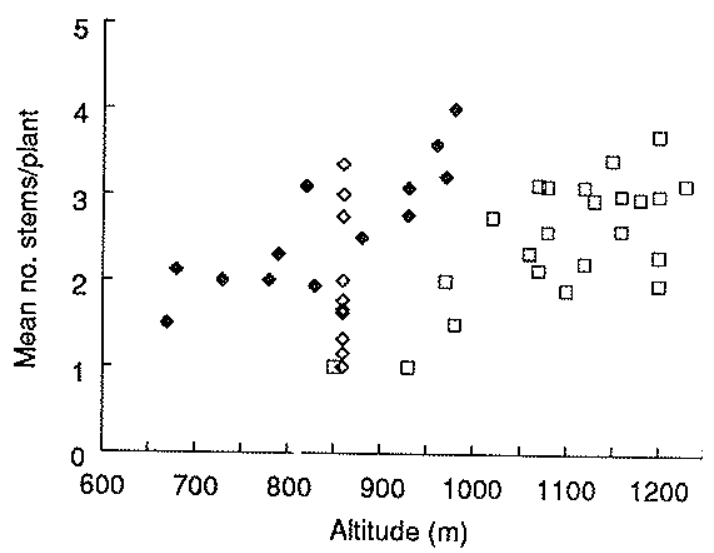

Fig. 11. The mean number of stems per plant for two Euculypfus species in response to altitude. $\square=$ E. coccifera; $=$ E. unigera; $\diamond=$ both species along transect.

tance of the variation in rainfall above $700 \mathrm{~m}$ is probably not great, as above this altitude even the lowest rainfall is sufficient to avoid drought on all but the shallowest soils. The increase in mist with altitude is likely to affect tree growth largely through the impact of moisture on leaves on photosynthetic performance. Minimum temperatures are unlikely to have much ecological significance on the steep slopes of Mt. Wellington, where cold air ponding does not occur. Gilfedder (1988) has shown that waterlogging, rather than severe frost, is the cause of treelessness in the subalpine valleys of the Mt. Wellington Plateau, and there are no records of frost kill of any eucalypt species on the mountain, despite the abundance of such records elsewhere in Tasmania (e.g. Davidson \& Reid 1987; Fensham \& Kirkpatrick 1992). However, there are good reasons to suspect that the amount of warmth suitable for photosynthesis and other plant physiological processes is a critical factor in the

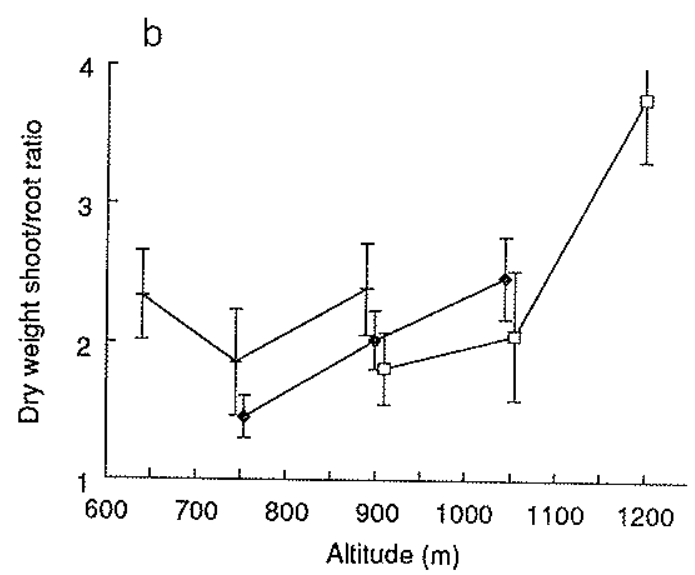

Fig. 12a-b. Mean seedling heights and shoot/root ratios in relation to altitude of seed source for a glasshouse provenance trial $(t$ s.e.m.). $\rightarrow=$ E. coccifera; $-=$ E. unigera; $-1=$ E. delegatensis. 
distribution of eucalypt species in Tasmania, with the boundaries between encalypt species, and between forest and alpine vegetation, increasing in altitude with increasing continentality (Kiskpatrick 1982, in press). The mechanism for this is unknown but may relate to the effect of temperature on the rate and duration of photosynthesis, as with the climatic treeline (Slatyer 1989). Thus, the altitude gradient is likely to be a close surrogate for the ecologically significant temperature gradient, and a less proximal surrogate for other correlated variables of lesser ecological significance.

The solar radiation gradient can affect growth rates either through its relationship to evapotranspiration (Kirkpatrick \& Nunez. 1980) or its relationship to the period available for photosynthesis. The high rainfall and low temperatures on the upper slopes of Mt. Wellington suggest that the latter relationship is likely to be more important in this study. During the growing season at high altitude, the variation in incident solar radiation will be much less than accounted for by the index used here, because the azimuth of the sun is much higher. Therefore, the difference in solar radiation with aspect at high altitude, during the period of a shorter growing season, will be much less than the difference over a longer growing season at low altitude. Additionally, the frequently occurring cloud base will cause all aspects to receive a greater proportion of diffuse light at high altitude. Consequently. maximum temperature, expressed as the length of the growing season, may be less related to solar radiation at higher than lower altitudes.

The gradient that is related to drainage and rockiness is very important on Mt. Wellington, with the main proximal effect on plant growth presumably involving excesses or deficiencies of moisture. However, moisture availability or excess cannot be measured directly in the many sites where there is a complete cover of large talus boulders. Rock cover itself is a poor indicator of soil development - road cuttings on Mt. Wellington sometimes show a well developed soil profile below a complete surface cover of rock. Thus, an indirect ordination score is likely to be a more accurate representation of this gradient than other surrogate variables.

\section{Genotypic variation}

The intraspecific trend in the mean heights of seedlings in the glasshouse experiment, suggests that the response curves of height growth rate on Mt. Wellington have a genotypic component. The intraspecific trend of decreasing height growth rate of seedings with altitude of seed source is consistent with the 'competitor' and 'stress-tolcrator' strategies of Grime (1979). However. the growth rate of 12 -week-old seedlings may not reflect the growth rate of adult plants. An indication that the seedling result is at least, in pan, a reflection of behaviour unique to seedlings, comes from a comparison of the seedling heights of E. umigera with $E$. delegatensis. This difference in growth rate of seedlings is not observed with adult plants (e.g. Fig. 4a). E. delegatensis and E. coccifera belong to the informal subgenus Monocalyptus, while E. urnigera belongs to the informal subgenus Symphyomyrtus (Pryor \& Johnson 1971). Some Symphyomyrtus species have a faster initial growth rate than Monocalyptus species (Duff et al. 1983).

The altitudinal trend in the shoot/root ratios of $E$. urnigera and $E$. coccifera suggests that seedlings from parents at higher altitudes may be responding to a shorter growing season and an abundance of moisture by allocating a large proportion of their resources to shoot production. This trend suggests that soil moisture may be limiting at lower altitudes (cf. Ladiges 1974). However, the seedlings from lower altitude parents allocate a greater proportion of photosynthate to roots, but grow faster in height. Seedlings from lower altitude parents are presumably involved in a trade-off between attaining height and maintaining sufficient root area. Height growth may be only one of several possibilities for shoot biomass allocation. Seedlings of E. delegatensis do not appear to be involved in the same trade-off as the other two species.

\section{The shapes and proximal meanings of the species responses}

Time did not permit the measurement of the heights and diameters of all stems within a quadrat, hence the measurement of only the largest or tallest plants in the quadrat. However, the largest or tallest stem is the individual that is most likely to become dominant as the forest gets older, assuming that suppression takes place between trees and between the stems of multi-stemmed trees.

Discriminating between basal coppice and seedlings was often difficult, so it was decided to not distinguish these two modes of regeneration. Although the growth rates of these two types of regeneration are probably different, when the form of regeneration was evident (e.g. live stems arising from the rootstock of bumt dead stems), it was clear that the most common and faster mode of regeneration was basal coppice. As this was true for all four species, this study is concerned with the growth rate of basal coppice. Plots which contained only seedlings of a species are a possible, although minor source of error. Identifying the extent of individual plants of $E$. umigera was another possible source of error, because multi-stemmed individuals often appeared as well dispersed groups of stems. 
The growth rate and basal area responses of the eucalypt species along environmental gradients on $\mathrm{Mt}$. Wellington are a mixture of straight lines and curves. There is relatively little overlap in the ranges of $E$. delegatensis and $E$. coccifera, while various mixures of either of these two species are found with $E$. umigera (Figs. 4a-f). E. coccifera and E. umigera are found mixed with $E$. johnstonii.

The upward shift of the altitudinal ranges of $E$. delegatensis, E. urnigera and E. coccifera with increasing solar radiation, the rapid attenuation of basal area at the boundaries between species and the relativities of their growth rates are consistent with a hypothesis that their zonation is the resull of their relative abilities to grow with different levels of warmth, at least on the shadier slopes. The contrast between curved responses on sunny slopes and linear responses on shaded slopes for $E$. unigera and $E$. coccifera may be taken to suggest stronger competition with $E$. delegatensis on the sunny than the shaded slopes. Such a hypothesis is consistent with the relativities of species growth rates on the different aspects. The fruncation of the sunny aspect range of E. delegatensis at $1000 \mathrm{~m}$, despite an overwhelming superiority in growth rate at this altitude, seems inconsistent with the above warnth-limit hypothesis. The susceptibility of $E$. delegatensis seedlings to death through freeze-thaw at the snow surface (Grose 1960) may provide a testable explanation.

The trees are less than half their potential height and the growth rate trends along environmental gradients may change as the forests mature. The age and therefore size of lignotubers of the multi-stemmed species may also influence growth rates. The increase in multi-stemming of E. cocciferc and E. umigera with altitude (Fig. 11) may be the result of slower growth rates and therefore less intense competition between individual stems of the one lignotuber, and/or a reduction in tree density. Stem thinning is evident on individual plants, where the smaller stems are often dying or dead.

\section{Stress and competition}

The concept of envirommental stress is difficult to operationalise with more than one species, given that a stressful environment for one species can be another's optimum. If we assume that low net productivity, as manifest in the total basal area of all species (Figs. 5 and $10)$, is an indicator of stressful conditions, E. coccifera is most stressed at high altitudes and on the margin of waterlogged areas, E. delegatensis is more stressed at the high than the low altitudinal extreme of its range, and $E$. unigera is most stressed where most waterlogged.

Basal area and growth rate responses are often similar at the stressful ends of gradients. For example, the responses are in the same direction at the high altitude end of the range of E. coccifera on exposed aspects (cf. Figs. $4 b$ and $4 f$ ), and the waterlogged end of the moisture gradient for the responses of E. urnigera (cf. Figs. 9 a and 9 b) and $E$. coccifera (cf. Figs. 9c and 9d). On the other hand, where growth conditions are becoming more productive, the basal area and growth rate responses often show opposite trends. For example, with the lower altitude part of the responses of $E$. delegatensis, $E$. umigera and $E$. coccifera to altitude on sheltered aspects (cf. Figs. $4 a$ and $4 \mathrm{e}$ ), growth rate increases with decreasing altitude, but basal area decreases.

Given that these growth rates are largely a response to the physical environment, it could be hypothesised that the basal area responses are indicative of species being outcompeted in more productive environments, which is consistent with the theory that competition (sensu Grime 1979) is less important in stressful environments (Grime 1979). If competition is occurring, it is presumably having a greater effect on seedlings than adult plants in the situations where no attenuation of height growth rate is evident in the coppice responses. In contrast, the height growth rate response of $E$. umigera to altitude on exposed aspects (Fig. 4b), could be a response to the physical environment at the stressful end of the gradient and a response to competition (with $E$. delegatensis) at the more productive end. Despite the conceptual problems with the definitions of 'stress' and 'competition' used by Grime (1979) (see Grace 1990), the difference between stress and competition is evident in this context.

Acknowledgements. David Keith and two anonymous referees made valuable comments on earlier drafts of the manuscript. We thank Bruce Brown (Mathematics Department, University of Tasmania) for advice in the analysis of the seedling height data.

\section{References}

Ashton, D.H. 1958. The ecology of Eucalyphts regnans fa. Muell.: the species and its frost resistance. Aust. J. Bot. 6 : 154-176.

Austin, M.P. 1972. Models and analysis of descriptive vegetation data. In: Jeffers, J.N.R. (ed.) Mathenatical models in ecology, pp. 61-86. Symp. Brit. Ecol. Soc. 12.

Auscin, M.P. 1980. Searching for a model for use in vegetation analysis. Vegetatio 42: 11-21.

Austin, M.P. 1985. Continuum concepts, ordination methods, and niche theory. Anu. Rev. Ecol. Syst. 16: 39-61.

Austin, M.P. \& Austin, B.O. 1980. Behaviour of experimental plant communities along a nutrient gradient. J. Ecol. 68: $89[-918$.

Austin, M.P. \& Smith, T.M. 1989. A new model for the 
continuum concept. Vegetatio 83: 35-47.

Austin, M.P., Groves, R.H., Fresco, L.M.F. \& Kaye, P.E. 1985. Relative growth of six thistle species along a nutrient gradient with multispecies competition. J. Ecol. 73: 667-684.

Barber, H.N. \& Jackson, W.D. 1957. Natural selection in action in Eucalyptus. Nature 179: 1267-1269.

Bowman, D.M.J.S. \& Kirkpatrick, J.B. 1986. Establishment, stippression and growth of Eucalyptus delegatensis R.T. Baker in multiaged forests. III. Intraspecific allelopathy, competition between adult and juvenile for moisture and nutrients, and frost damage to seedlings. Aust. J. Bot. 34: $81-94$.

Bray, J.R. \& Curtis, J.T. 1957. An ordination of the upland forest communities of southern Wisconsin. Ecol. Monogr. 27: 325-349.

Caine, N. 1983. The motntains of northeast Tasmania. Balkema, Rotterdam.

Curtis, W.M. \& Morris, D.M. 1975. The student's flora of Tasmania. Part 1. Government Printer, Hobart.

Davidson, N.J. \& Reid, J.B. 1987. The influence of hardening and waterlogging on the frost resistance of subalpine eucalypts. Aust. J. Bot. 35: 91-101.

Duff, G.A., Reid, J.B. \& Jackson, W.D. 1983. The occurrence of mixed stands of the Eucalyptus subgenera Monocalyptus and Symphyomyrtus in south-eastern Tasmania. Aust. I. Ecol. 8: $405-414$.

Fensham, R.J. \& Kirkpatrick, J.B. 1992. The eucalypt forestgrassland/grassy woodland boundary in central Tasmania. Aust. J. Bot. 40: 123-138.

Fresco, L.F.M. 1982. An analysis of species response curves and of competition from field data: some results from heath vegetation. Vegetatio 48: 175-185.

Gilfedder, L. 1988. Factors influencing the maintenance of an inverted Eucalyptus coccifera tree-line on the Mt. Wellington Plateau, Tasmania. Aust. J. Ecol. 13: 495-503.

Grace, J.B. 1990. On the relationship between plant traits and competitive ability. In: Grace, J.B. \& Tilman, D. (eds.) Perspectives on plant competition, pp. 51-65. Academic Press, San Djego, CA.

Grime, J.P. 1979. Plant strategies and vegetation processes. John Wiley \& Sons, Chichester.

Grose, R.J. 1960. The silvyculture of Eucalyptus delegatensis R.T. Baker. PhD thesis, University of Melboume, Melbounne.

Kessel, S.R. 1979. Gradient modelling: resource and fire management. Springer-Verlag, New York, NY.

Kirkpatrick, J.B. 1982. Phytogeographical analysis of Tasmanian alpine floras. J. Biogeogr. 9: 255-271.

Kirkpatrick, J.B. In press. Grassy and subalpine vegetation. In Hill, R.S., Brown, M.J. \& Reid, J.B. (eds.) The Vegetation of Tasmania. Government Printer, Hobart.

Kirkpatrick, J.B. \& Nunez, M. 1980. Vegetation-radiation relationships in mountainous terrain; cucalypt-dominated vegetation in the Risdon Hills, Tasmania. J. Biogeogr. 7 : 197-208.

Ladiges, P.Y. 1974. Differentiation in some populations of Eucalyptus viminalis Labill. in relation to factors affecting seedling establishment. Aust. J. Bot. 22: 471-487.
Lee, R. 1978. Forest Microclimatolog): Columbia University Press, New York, NY.

Loveday, J. 1955. Reconaissance soil map of Tasmania l: 6.3 360. Hobart Sheet 82. CSIRO, Hobart.

Minchin, P.R. 1989. Montane vegetation of the Mt. Field massif, Tasmania: a test of some hypotheses about properties of community patterns. Vegetatio 83: 97-110.

Minchin, P.R. 1990. DECODA User's manual. Amtech Pty. Lid., Canberra.

Muelier-Dombois, D. \& Elsenberg, H. 1974. Aims and methods of vegetation ecology: John Wiley \& Sons, New York, NY.

Nicolis, K.D. 1961. Soil fomation on dolerite in Tasmania. Dolerite - A Symposium, pp. 204-209. Geology Department, University of Tasmania, Hobart.

Nunez, M. 1983. Estimation of solar radiation received on slopes in Tasmania. Pap. Proc. R. Soc. Tasm. 117: 153159.

Nunez, M. \& Colhoun, E.A. 1986. A note on air temperature lapse rates on Mount Wellington, Tasmania. Pap. Proc. $R$. Soc: Tasm. 120: 1 [-15.

Ogden, J. \& Powell, J.A. 1979. A quantitative description of the forest vegetation on an altitudinal gradient in the Mount Field Nationa! Park, Tasmania, and a discussion of its history and dynamics. Aust. J. Ecol. 4: 293-325.

Parsons, R.F. 1968. The significance of growth-rate comparisons for plant ecology. Am. Nat. 102: 595-597.

Pryor, L.D. \& Johnson, L.A.S. 1971. A classification of the eucalypts. Australian National University, Canberal.

Robertson, P.A., MacKenzic, M.D. \& Elliott, J.F. 1984. Gradient analysis and classification of the woody vegetation for four sites in southern Illinois and adjacent Missouri. Vegetatio 58: 87-104.

Slatyer, R.O. 1989 Alpine and valley bottom treelines. In: Good, R. (ed.) The scientific significance of the Australian Alps, pp. 169-184. Australian Alps National Parks Liaison Committee, Canberra.

Villagrán, C., Armesto, J.J. \& Kalin Arroyo, M.T. 1981. Vegetation in a high Andean transect between Turi and Cerro León in Northern Chile. Vegetatio 48: 3-16.

Waring, R.H. \& Major; J. 1964. Some vegetation of the California coastal redwood region in relation to gradients of moisture, nutrients, light, and temperature. Ecol. Monogr: 34: 167-215.

Werger, M.J.A., Louppen, J.M.W. \& Eppink, J.H.M. 1983. Species performances and vegetation boundaries along an environmental gradient. Vegetatio 52: 141-150.

Whittaker, R.H. 1956. Vegetation of the Great Smoky Mountains. Ecol. Monogr: 26: 1-80.

Whittaker, R.H. 1978. Direct gradient analysis. In: Whittaker, R.H. (ed.) Ordination of plant communities, pp. 3-50. Junk, The Hague.
Received 5 May 1992; Revision received 4 Jantary 1993; Accepted 2 July 1993. 